\title{
ISLAM SASAK: POLA KEBERAGAMAAN KOMUNITAS ISLAM LOKAL DI LOMBOK
}

\author{
Oleh: Abmad Amir Ariz*
}

\section{Abstract:}

This paper aims to describe the characteristic appears in the religious identity of Sasake community in Lombok, and to understand Wetu Telu that was considered an uncompleted process of islamization by presently most Muslims in the region. According to the writer Islam Sasak, including Waktu Lima as promoted by tuan guru, is combination of tradition, cultural, and religious values. This may be seen from various rituals which tend to emphasize negotiation between Islamic texts and social contexts. Islamic local leaders have succeeded to make the opened-religiosity system like ritual of muludan. Another point of view, merariq tradition still accommodated pesuke which is the dominant culture in Sasak. Based on this view the writer underline that dialectical processes between Islam and Sasak tradition still going on through various local traditions from the past to the present.

مستخلص

يسعى هذا البحث إلى إبراز خصائص الهوية الدينية لمحتمعات عرق الساساك في لومبوء، وذلك ألكن طريق إخضاع مذهب "الأوقات الثلائة" للدراسة، ذلك المذهب الذي الذي يُنظر إليه على أنه عملية أسلمة لم الم

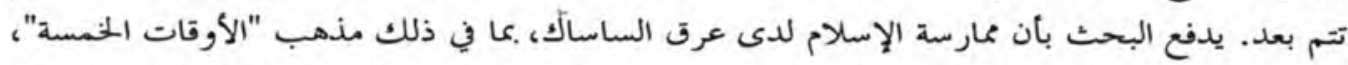
الذي يدعو له رجالات الدين (توان غورو)، تعتبر مزيجا من التقاليد والثقافة المحلية والقيم الدينية الإسلامية. ويقدم البحث أمثلة على هذا المزيج تتحسد في الطقوس الدينية والاجتماعية التي تحاول دمبج

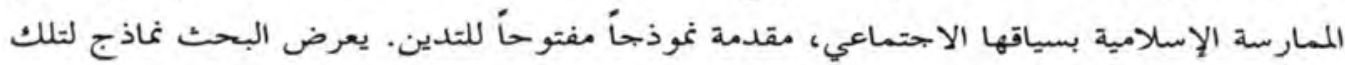
الطقوس مثل طقس مولودان (المولد النبوي) وميراريك (الزواج)؛ ذلك الزواج الذي لمّي يزل يكوي

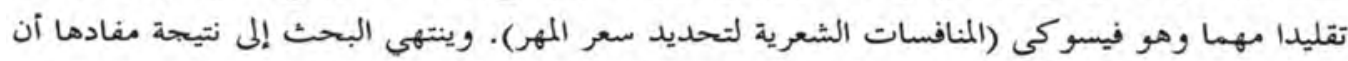
ثمة عملية جدلية بين الممارسة الإسلامية لدى عرق الساساك وتقاليده، وأن هذه العملية مرشحة للاستمرار في المدى المنظور.

Keywords: Islam Sasak, Wetu Telu, Tuan Guru, dan Tradisi Lokal ahamiraziz@yahoo.co.id 


\section{A. Pendahuluan}

Studi-studi tentang Islam lokal belakangan ini mendapat perhatian lebih dibanding era sebelumnya. Penelitian Geertz misalnya, amat populer tetapi sekaligus kontroversial karena cara pandangnya yang dikotomis dalam mendeskripsikan santri dan abangan. ${ }^{1}$ Sementara itu Noer juga membedakan secara tajam antara Islam tradisional dan Islam modern. Islam tradisional dipandang sebagai Islam berwajah sinkretis, sedangkan Islam modern adalah Islam sebagaimana yang ada di tanah asalnya. ${ }^{2}$

Pandangan seperti itu tidak bisa disalahkan, karena setiap usaha pemetaan sosial-keagamaan pasti ada lebih dan kurangnya. Jika hasil pemetaan itu dipahami secara kaku, maka tidak akan mengindahkan adanya kemungkinan proses negosiasi antara adat dan Islam. Pada gilirannya, ini akan memunculkan pandangan hitamputih antara Islam dengan tradisi lokal.

Kecenderungan pandangan kontemporer justru menghargai ragam ekspresi lokalitas. Khazanah Islam lokal yang tersebar di pelbagai daerah amat kaya dengan keyakinan dan praktik keagamaan. Meskipun sebagian ritual hanya berbasis budaya yang tidak ada relevansinya dengan agama, namun acapkali banyak ritual yang merupakan kolaborasi dinamis antara nilai-nilai Islam dan tradisi setempat. ${ }^{3}$

Ketika Islam bertemu dengan tradisi lokal, wajah Islam berbeda dari tempat satu dengan lainnya. Menyikapi masalah ini ada dua hal yang patut dicatat. Pertama, Islam itu sebenarnya lahir sebagai produk lokal yang kemudian diuniversalisasikan dan ditransendensi, sehingga kemudian menjadi universal. Dalam konteks Arab, yang dimaksud dengan Islam sebagai produk lokal adalah Islam yang lahir di Arab, tepatnya daerah Hijaz, dalam situasi Arab dan pada waktu itu ditujukan sebagai jawaban terhadap persoalan-persoalan yang berkembang di sana. Islam Arab tersebut terus berkembang ketika bertemu dengan budaya dan peradaban Persia dan Yunani, sehingga kemudian Islam mengalami proses dinamisasi kebudayaan dan peradaban.

Kedua, walaupun diyakini bahwa Islam itu wahyu Tuhan yang universal, namun ia dipersepsi oleh para pemeluknya sesuai dengan pengalaman, problem, kapasitas, intelektual, sistem budaya, dan segala keragaman masing-masing di dalam komunitasnya. ${ }^{4}$

1 Clifford Geertz, Abangan, Santri, Priyayi dalam Masyarakat Jawa, alih bahasa Aswab Mahasin, Cet. 3, (Jakarta: Pustaka Jaya, 1989).

2 Lihat Deliar Noer, Gerakan Modern Islam di Indonesia 1900-1942, (Jakarta: LP3ES, 1996).

3 Mark R. Woodward, Islam Jawa Kesalehan Normatif Versus Kebatinan, alih bahasa Hairus Salim, (Yogyakarta: LKiS, 1999).

4 Nurcholish Madjid, "Islam dan Budaya Lokal: Masalah Akulturasi Timbal Balik", dalam Islam Doktrin dan Peradaban, (Jakarta: Paramadina, 1992), hal. 542-554. 
Dengan demikian, memang justru kedua dimensi ini perlu disadari, yang di satu sisi Islam sebagai universal, dan di sisi lain budaya lokal sebagai bentuk kearifan (local wisdom) yang dapat menopang eksistensi dalam penerapan Islam itu sendiri.

Kehadiran varian Islam lokal sendiri jelas tak terelakkan. Ia imbas lanjut dari ketidakmungkinan Islam sebagai agama hadir dengan melepas diri dari realitas. Agama selalu merupakan hasil dialog antara dirinya dan kenyataan di mana ia muncul. Ketika ia menjumpai varian kultur lokal, maka yang segera berlangsung adalah aneka proses simbiose yang saling memperkaya. Muncullah beragam varian Islam. Ada Islam Melayu, Islam Jawa, Islam Madura, Islam Bugis, dan seterusnya, termasuk Islam Sasak, ${ }^{5}$ yang masing-masing mengetengahkan karakter yang khas.

Tulisan ini bermaksud memberi deskripsi dan analisis terhadap pertemuan tradisi lokal dengan Islam dalam wujud Islam Sasak. Pertemuan ini mencerminkan adanya dialog dan sintesis budaya dan norma Islam, di mana kosmologi lokal, struktur dan formasi sosial, dan berbagai ragam ritual masa lalu dinegosiasikan. Titik tekan tulisan ini hendak mengetengahkan dua varian masyarakat Sasak, yaitu komunitas Wetu Telu dan Islam Waktu Lima, yang keduanya tidak perlu dipandang sebagai pihak yang bertentangan. Bentuk-bentuk ritual dan tradisi yang masih hidup dan berkembang juga akan disajikan untuk melihat sejauh mana Islam bisa mewarnai dalam budaya lokal masyarakat Sasak.

\section{B. Komunitas Wetu Telu versus Islam Waktu Lima}

Secara umum sering dinyatakan bahwa corak Islam yang berkembang dalam masyarakat Sasak di Pulau Lombok pada praktiknya ada dua, yaitu Islam Wetu Telu dan Islam Waktu Lima. Pembagian itu tidak sepenuhnya bisa diterima oleh karena menurut sebagian orang Sasak, Wetu Telu merupakan tradisi dan bukan merupakan agama. Karena itu term Islam Wetu Telu kurang tepat, lebih tepat diistilahkan dengan komunitas Wetu Telu. Meskipun demikian, sejumlah kepercayaan antara dua kelompok ini banyak yang mirip, dan pada perkembangannya terjadi dialog kultural yang damai, meskipun terkadang diwarnai pertentangan dan saling berebut pengaruh.

Menurut komunitas Wetu Telu, "wetu" sering dikacaukan dengan "waktu". Padahal menurut mereka "wetu" berasal dari kata "metu" yang berarti "muncul" atau "datang dari". Maksudnya, bahwa semua makhluk hidup itu muncul (metu)

5 Lihat disertasi Ahmad Abd. Syakur, Islam dan Kebudayaan Sasak; Studi tentang Akulturasi Nilai-Nilai Islam ke dalam Kebudayaan Sasak, (Yogyakarta: Pascasarjanan IAIN Sunan Kalijaga, 2002). 
melalui tiga macam sistem reproduksi yang diciptakan Tuhan: menganak (melahirkan) seperti manusia, menteluk (bertelur) seperti burung, dan mentiuk (berkembang biak dari benih) seperti buah-buahan. ${ }^{6}$ Ini merupakan dasar pemahaman kosmologis yang tertanam kuat di kalangan mereka.

Sebagai simbolnya terdapat pahatan patung kayu yang disebut Paksi Bayan yang menampilkan sosok seekor singa yang berada di puncak mimbar masjid kuno Wetu Telu di Bayan Lombok Barat. Seorang kiai biasanya duduk di mimbar ini saat memberikan khutbah dalam memperingati hari besar Islam seperti saat lebaran. Pada Paksi Bayan itu juga terdapat pahatan lain yang merepresentasikan tiga sistem reproduksi: kijang melambangkan kelahiran anak-anak, unggas merepresentasikan burung yang bertelur sedang kelapa, padi dan kapas melambangkan aneka tumbuhan yang berkembang-biak dari benih dan buah.

Selain itu, mereka memiliki pemahaman tentang adanya ketergantungan antara antara jagad besar (makrokosmos) yang terdiri atas matahari, bulan, bintang, dan planet lain, serta jagad kecil (mikrokomos) yang berisikan manusia dan mahluk lain. Ketergantungan jagad kecil kepada jagad besar tercermin dalam kebutuhan terhadap tanah, udara, air, dan api. Pada saat yang sama jagad besar juga tergantung pada jagad kecil dalam hal pemeliharaan dan pelestarian. Ketergantungan semacam itu menyatukan dua dunia tersebut dalam suatu keseimbangan, dan karena itulah tatanan alam (kosmologis) bekerja.

Masyarakat Wetu Telu percaya pada Tuhan yang menciptakan Adam dan Hawa sebagai manusia-manusia pertama. Dalam praktiknya keagamaan masyarakat ini sarat diwarnai dengan bermacam-macam kepercayaan tentang roh, sebagai mediator mereka sewaktu berkontemplasi dengan Tuhan. Mereka juga percaya dan sangat menghargai ritual siklus kehidupan. Bagi mereka, setiap siklus diawali maupun diakhiri harus diawali dengan suatu ritual khusus sebagai pertanda mengarah pada status yang lebih tinggi. Tidak heran jika banyak ritual yang tetap lestari, seperti ritus buang au (upacara kelahiran), ngurisang (upacara pemotongan rambut), ngitanan (khitanan), merosok/bekikir (meratakan gigi), merariq (melarikan perempuan untuk dinikahi), metikah (perkawinan) begawe pati (ritual kematian dan pasca kematian), dan sebagainya. ${ }^{7}$

${ }^{6}$ Erni Budiwanti, Islam Sasak Wetu Telu versus Waktu Lima, alih bahasa Noor Cholis dan Hairus Salim HS, (Yogyakarta: LKiS, 2000), hal. 136.

7 Team Penyusun, Monografi Daerah Nusa Tenggara Barat (Jakarta: Departemen Pendidikan dan Kebudayaan, 1977), hal. 79-89. 
Masih banyak kepercayaan yang diyakini komunitas ini. Namun pada intinya bertumpu pada pengetahuan tentang tradisi yang dipelihara secara turun temurun, ${ }^{8}$ bukan tentang agama (Islam) dalam makna legal-normatifnya. Dengan demikian, adat menjadi referensi sentral dalam peribadatan Wetu Telu. Inilah pengertian dan kedudukan kelompok Wetu Telu sebagai komunitas tradisional masyarakat Sasak. Makna asli mereka yang seperti itu merupakan pengertian model pertama yang disepakati oleh orang-orang Lombok dan sejumlah penulis/peneliti.

Namun demikian, seiring berkembangnya Islam di Lombok sebagai agama mayoritas membuat komunitas adat ini memilih Islam sebagai identitas keagamaannya, meskipun praktik adat tetap mereka pegang. Kenyataan inilah yang memunculkan pengertian baru dari Wetu Telu menjadi Islam Wetu Telu.

Menurut kalangan yang mengidentifikasi mereka sebagai Islam Wetu Telu, mereka ini hanya mengenal tiga rukun Islam, yaitu dua kalimat syahadat, shalat, dan puasa. Shalat yang dilaksanakan adalah shalat Jumat, shalat Idul Fitri dan Idul Adha serta shalat jenazah. Puasa Ramadhan dilakukan hanya tiga hari yaitu awal, tengah dan akhir bulan.'

Munculnya pemahaman keagamaan dan pelaksanaan ritual Islam secara minimal ini jika ditelusuri ternyata berkaitkan dengan proses dakwah Islam yang belum tuntas dilakukan para penyebar Islam awal. Dalam proses penyebarannya, ternyata ajaran-ajaran Islam masih sulit diterima secara bulat oleh orang-orang Sasak. Kepercayaan animisme dan dinamisme, yang merupakan warisan nenek moyang masih belum bisa mereka tinggalkan. Di samping itu, karena daya lentur ajaran Islam dan tata nilai yang telah berkembang dalam kehidupan masyarakat sebelum datangnya Islam, tidak serta merta diganti. Akibatnya masih ada budaya lama yang masih diterapkan bersamaan dengan ajaran Islam yang baru mereka terima.

Suburnya perkembangan Wetu Telu didukung oleh kondisi penguasa Hindu yang melakukan tindakan hingga mengakibatkan terhambatnya pembinaan kehidupan agama Islam dan menyebabkan timbulnya penyimpangan-penyimpangan dari ajaran-ajaran yang terdapat dalam Al-Qur'an dan Hadits. ${ }^{10}$ Penguasa

8 Kepercayaan Wetu Telu bersumber dari campuran banyak unsur: Hindu-Majapahit, tradisi lokal setempat, dan pengaruh orang-orang Bali karena orang Lombok sejak tahun 1740 hingga 1894 berada di bawah control raja-raja Bali. Lihat John Ryan Bartholomew, Alif Lam Mim: Kearifan Masyarakat Sasak, alih bahasa Imron Rosyidi, (Yogyakarta: Tiara Wacana, 2001), hal. 96.

9 Fathurrahman Zakaria, Mozaik Budaya Orang Mataram, (Mataram: Yayasan Sumurmas AlHamidy, 1998), hal. 139.

10 Soenyata Kartadarmadja dan Sutrisno Kutoyo, ed., Sejarah Kebangkitan Nasional Daerah NTB, (Jakarta: Pusat Penelitian Sejarah dan Budaya Depdikbud, 1978), hal. 27-29. 
menekan orang-orang yang akan menunaikan ibadah haji sehingga orang-orang yang naik haji menjadi sangat sedikit jumlahnya. ${ }^{11}$

Belanda semakin memperjelas demarkasi antara Hindu dan Islam, Adat dan Islam dan seterusnya sehingga sebagai realitas akhir dari pola keagamaan masyarakat Sasak adalah: (1) Islam Sunni (ortodoks) yang pada akhirnya populer dengan Waktu Lima, (2) Hindu-Bali, (3) Boda yang merupakan pola keagamaan primordial dan pengejewantahan adat dan tradisi yang kuat, dan (4) Kolaborasi beragam agama mulai dari Boda, Hindu, dan Islam yang akhirnya di sebut dengan Wetu Telu. ${ }^{12}$

Pada perkembangannya, komunitas Wetu Telu sudah banyak yang melaksanakan ajaran Islam dengan sempurna berkat kegigihan para Tuan Guru yang sudah menimba ilmu pengetahuan di Mekkah sejak abad ke-19. Mereka berdakwah dan membimbing masyarakat kepada cara-cara ritual Islam Waktu Lima seperti, TGH. Ali Batu, Guru Bangkol, TGH. Muhammad Siddiq, TGH. Zainuddin Abdul Madjid, TGH. Saleh Hanbali, TGH. Makmun, dan masih banyak lagi. Mereka merupakan penyiar Islam yang menekankan aspek fiqh berupa kewajiban pokok seperti shalat, puasa, zakat dan haji, dan bahkan kadang ditambah dengan wirid thariqat bagi mereka yang dianggap sudah layak. Tarekat ini pada akhir abad ke-19 berperan besar dalam pemberontakan melawan Belanda. ${ }^{13}$

Para Tuan Guru pimpinan Islam Waktu Lima ini tidak memberangus budayabudaya dan tradisi lokal masyarakat setempat. TGH. Mutawalli misalnya, adalah seorang tokoh yang mendakwahkan Islam dengan pendekatan kultural. Keyakinan lokal masyarakat dibiarkan saja hidup. Dia mempelajari mitologi pada komunitas Wetu Telu, mula-mula dengan cara mengutus murid-murid kepercayaannya untuk menghimpun legenda dan mitos setempat dari para tetua desa. ${ }^{14}$ la memahami bahwa komunitas Wetu Telu sangat suka memuja masa lalu, dan karena itu ia menampilkan diri berminat mempelajari silsilah penduduk. Dengan modal itu dia dapat secara leluasa mengenal kharakter, budaya, dan kepercayaan masyarakat setempat yang membuatnya dapat begitu merakyat.

11 Yayasan Bhakti Wawasan Nusantara, Profil Propinsi NTB, (Jakarta: Yayasan Bhakti Wawasan Nusantara, 1992), hal. 45.

12 Kamarudin Zaelani, "Dialektika Islam dengan Varian Kultur Lokal dalam Pola Keberagamaan Muslim Sasak”, Jurnal Ulumuna IAIN Mataram, Vol. IX Edisi 15 No.1 (Januari-Juni 2005), hal. 48-69.

13 Martin van Bruinessen, Tarekat Naqsyabandiyah di Indonesia, (Bandung: Mizan, 1992), hal. 28.

14 Budiwanti, Islam Sasak..., hal. 292. 
Dakwah kultural semacam itu ternyata berhasil menampilkan wajah Islam yang membumi. ${ }^{15}$ Dalam pribumisasi Islam tergambar bagaimana Islam sebagai ajaran yang normatif dari Tuhan diakomodasikan ke dalam kebudayaan yang berasal dari manusia tanpa kehilangan identitasnya masing-masing. Pandangan semacam ini muncul sebagai respons atas proses Arabisasi yang dilakukan oleh sebagian kalangan Islam radikal yang mempunyai keinginan mengidentifikasi Islam dengan budaya Arab. Pribumisasi Islam bermaksud menghindari terjadinya polarisasi antara agama dengan budaya setempat. Artinya, menjadikan agama dan budaya agar tidak saling mengalah, melainkan membuat pola hubungan dalam nalar keagamaan dengan berusaha menemukan jembatan antara agama dan budaya.

\section{Potret Tradisi dan Ritual Islam Sasak}

Terlepas dari kedua pola keberagamaan Wetu Telu dan Waktu Lima, Muslim Sasak dikenal sangat religius, namun juga relatif kental dalam mempertahankan tradisi. Sekuat apapun Islam normatif yang dianutnya tetap saja selalu ada unsur budaya yang masuk, sementara budaya tersebut juga berkembang dari waktu ke waktu.

Secara umum, keduanya tidak dipertentangkan secara dikotomis oleh muslim Sasak. Mereka lebih menyukai model Islam kolaborasi-kreatif, yang mana hal itu ditandai dengan keengganannya membunuh tradisi lokal, bahkan sebaliknya, tetap mengapresiasinya dengan cara melakukan akulturasi-kritis sehingga melahirkan wajah Islam moderat. Berikut ini dua contoh praktik ritual dan tradisi yang mencerminkan corak keberagamaan kolaborasi-kreatif dalam Islam Sasak.

\section{Tradisi Maulid}

Tradisi perayaan maulid bagi komunitas Islam Sasak terbilang unik. Berbeda dengan di daerah lain, perayaan maulid di Lombok digelar sangat meriah yang dilakukan sepanjang bulan. Berbagai pesta tradisi seperti panjat pinang dan aneka lomba lainnya diikuti tidak hanya oleh anak-anak tetapi juga orang dewasa. Di samping acara adat, ritual keagamaan juga tetap mendapat prioritas. Yang menarik, berlangsungnya muludan itu identik dengan "slametan besar" dalam budaya jawa, atau dalam istilah lokalnya disebut begibung (makan besar secara bersama-sama).

15 Pada perkembangannya muncul gagasan pribumisasi Islam yang diungkapkan oleh Gus Dur. Lihat Abdurrahman Wahid, Pergulatan Negara, Agama, dan Kebudayaan, (Jakarta: Desantara, 2001). 
Secara tipikal tradisi ini unik karena hampir semua orang Lombok merayakannya, baik secara individu maupun komunal. ${ }^{16}$ Masing-masing keluarga mengundang keluarganya yang lain dari desa lain untuk menghadiri hajatan di rumahnya, dan pada saat lain dia diundang oleh keluarganya yang lain. Demikian seterusnya, secara bergiliran dilakukan, karena waktu pelaksanaan muludan sengaja dibuat tidak sama waktunya antara satu desa dengan desa lainnya.

Hidangan makanan yang disajikan bervariasi, akan tetapi pada umumnya mereka menyembelih ternak seperti ayam, kambing, sapi, dan bahkan kerbau. Adapaun jenis jajanan yang sering mereka bikin adalah jajan-jajan lokal, yaitu banget rusul, jaje bawang, jaje goreng, jaje peyek, poteng jaje tujak, kaliderem, kuping gajah, renggi, angin-angin, wajik, pangan, iwel, dan banget rusul. Jaje yang disebut terakhir ini bahan bakunya dari ketan dan santan yang dibubuhi umbi kunyit agar berwarna kekuning-kuningan. Setelah dikemas sedemikian rupa, jajan ini menjadi lengket.

Term banget memiliki arti "sangat lengket" sedangkan term rusul sendiri bermakna Nabi Muhammad yang diutus Allah, sehingga kalau digabungkan menjadi satu kata dapat bermakna bahwa dengan adanya jajan ini diharapkan bagi umat Islam Sasak menanamkan sikap cinta dan kasih sayang yang lengket kepada Rasulullah dengan mentaati segala sunnah yang telah disampaikan olehnya.

Dari rangkaian ritual muludan dapat dipahami bahwa ini merupakan ritual individu dan komunal yang menyerap berbagai budaya masyarakat setempat. Hal ini wajar mengingat budaya merupakan sistem simbol yang berfungsi untuk mengarahkan tingkah laku umat beragama. ${ }^{17}$

Meskipun demikian, pemahaman dan praktik tradisi maulid pada komunitas Islam Sasak amat dinamis. Beberapa elit lokal terutama dari kalangan Tuan Guru mulai banyak yang mengkritik terhadap tradisi maulid setempat yang dinilainya terlalu boros, padahal masih banyak persoalan sosial-keagamaan yang membutuhkan penanganan segera dan memerlukan dana yang tidak sedikit. Mereka berargumen, adalah lebih bermanfaat mengumpulkan uang untuk mengembangkan pendidikan Islam daripada untuk "makan-makan besar" dalam rangka muludan.

Perubahan-perubahan kreatif itu terutama sangat dipengaruhi oleh peran para Tuan Guru dan tokoh masyarakat. Peran itu misalnya dapat ditemukan pada saat mereka melakukan proses pembiasaan dan penyadaran bagi masyarakat, di mana mereka lebih banyak memposisikan diri sebagai media transformasi. Gagasan kreatif

16 Bartholomew, Alif Lam Mim..., hal. 121.

17 Clifford Geertz, The Interpretation of Culture, (London: Sage Publication, 1970), hal. 65. 
dari Tuan Guru dalam menafsirkan simbol-simbol tertentu pada lingkungan budaya Islam Sasak merupakan kunci bagi terbentuknya local cultural reproduction sehingga pelestarian tradisi lokal dapat terjaga secara dinamis. Tradisi hajatan besar yang sudah berakar kuat dalam masyarakat sejak dahulu itu tetap dibiarkan, sedangkan ruh perayaan maulid ditanamkan lewat pendekatan kultural.

Hal ini sesuai dengan karakter penyebaran Islam awal di Lombok, sebab saat itu para penyebar Islam bertindak sangat hati-hati dan lemah lembut serta tidak revolusioner. Ajaran agama disampaikannya secara bertahap sesuai dengan kemampuan mereka yang menerimanya. Inilah proses dialog budaya dan model adaptasi yang tidak saling menafikan. Dalam konteks ini, teori Bassam Tibi menemukan relevansinya. Dia merekomendasikan bahwa akomodasi kultural selayaknya dilakukan oleh masyarakat Islam, yakni upaya untuk membuka diri terhadap perubahan, sebagai proses akulturasi, asimilasi, difusi, dan adaptasi. Islam dipahami sebagai kumpulan dengan variasi interpretasi berada dalam konteks lokalitas tradisi lokal. Pada pokoknya yang utama adalah memperlakukan Islam sebagai sistem simbol untuk memahami dunia dan lingkungan kebudayaan tertentu. ${ }^{18}$

Konsep Islam kreatif yang dikonstruks melalui proses dialektik ini mencirikan karakter Islam dinamis yang dihasilkan melalui interaksi secara terus-menerus dengan tidak memandang remeh masuknya unsur-unsur lokal. Pola demikian lebih mengarah kepada sikap toleran karena memandang Islam bukan sebagai produk akhir yang tidak dapat ditafsirkan kembali oleh para penganutnya. Namun sebaliknya, Islam dipandang sebagai proses yang sedang terbentuk (becoming) sehingga memungkinkan aktifitas muslim Sasak berperan aktif sesuai fitrah kemanusiaan dan kondisi sosial setempat.

\section{Merariq}

Kawin lari, dalam arti dibawanya pergi calon pengantin perempuan oleh calon pengantin laki-laki, merupakan tradisi pra-penikahan yang masih diterapkan di Lombok, ${ }^{19}$ yang diistilahkan dengan merariq. ${ }^{20}$ Kawin lari (merariq) menurut satu

18 Lihat Bassam Tibi, Islam and the Cultural Accommodation of Social Change, (San Francisco: West view Press, 1991).

19 Solichin Salam, Lombok Pulau Perawan: Sejarah dan Masa Depannya, (Jakarta: Kuning Mas, 1992), hal. 22.

20 Istilah merariq berasal dari bahasa Sasak berari (berlari) yang mengandung dua arti. Pertama, lari. Ini adalah arti yang sebenarnya. Kedua, keseluruhan pelaksanaan perkawinan menurut adat Sasak. Pelarian merupakan tindakan nyata untuk membebaskan gadis dari ikatan orang tua serta keluarganya. Lihat Tim Departemen P dan K, Adat dan Upacara Perkawinan Daerah Nusa Tenggara Barat, (Jakarta: Depdikbud, 1995), hal. 33. 
versi dianggap sebagai budaya produk lokal dan merupakan ritual asli (genuine) dari leluhur masyarakat Sasak yang sudah dipraktikkan oleh masyarakat sebelum datangnya kekuasaan Bali di Lombok maupun kolonial Belanda. Namun menurut versi lain, merariq dianggap budaya produk impor yang tidak dipraktikkan masyarakat Sasak sebelum datangnya Hindu-Bali. Pendapat ini didukung oleh sebagian masyarakat Sasak dan dipelopori oleh tokoh agama, khususnya para tuan guru.

Kawin lari (merariq) dipahami dan diyakini sebagai bentuk kehormatan atas harkat dan martabat keluarga perempuan. Atas dasar keyakinan ini, seorang gadis yang dilarikan sama sekali tidak dianggap sebagai sebuah wanprestasi (pelanggaran sepihak) oleh keluarga lelaki atas keluarga perempuan, tetapi justru dianggap sebagai prestasi keluarga perempuan. Seorang gadis yang dilarikan merasa dianggap memiliki keistimewaan tertentu, sehingga menarik hati lelaki. Ada anggapan yang mengakar kuat dalam struktur mental masyarakat di Lombok bahwa dengan dilarikan berarti anak gadisnya memiliki nilai tawar ekonomis yang tinggi. Konsekuensinya, keluarga perempuan merasa terhina jika perkawinan gadisnya tidak dengan kawin lari. ${ }^{21}$

Terjadinya kawin lari hampir selalu berlanjut ke proses tawar-menawar tentang besaran biaya yang diminta keluarga perempuan, yang disebut pesuke. Proses nego berkaitan dengan jumlah pesuke yang biasanya dilakukan dalam acara mbait wali sangat kental dengan nuansa bisnis. Semakin tinggi tingkat pendidikan dan tingkat sosial anak dan orang tua semakin tinggi pula nilai tawar sang gadis. Sebaliknya, semakin rendah tingkat sosial dan tingkat pendidikan anak serta orang tua semakin rendah pula nilai ekonomis yang ditawarkan. ${ }^{22}$

Dalam merariq, khususnya tentang permintaan pesuke ini, norma Islam dinegosiasikan secara kreatif dan diberikan makna baru. Sebagai konsekuensinya, sedikit "penyimpangan" dari teks-teks agama tidak dapat dihindari. Norma agama menghendaki bahwa segala ritual hendaknya dipraktikkan secara sederhana, tidak memberatkan, dan juga tidak boros, sebagaimana ditekankan oleh Al-Qur'an dan Sunnah. ${ }^{23}$ Tradisi pesuke misalnya, merupakan kegiatan dalam dimensi sosial

21 M. Nur Yasin, "Kontekstualisasi Doktrin Tradisional di Tengah Modernisasi Hukum Nasional Studi tentang Kawin Lari (merariq) di Pulau Lombok", dalam Jurnal Istinbath Fak. Syariah IAIN Mataram, Vol. 4, No. 1 (Desember 2006), hal. 63-90.

22 Abdullah Mustafa dan Zaenuddin Mansyur, "Fenomena Pesuke pada Adat Perkawinan Suku Sasak: Kajian Sosiologi Hukun Islam atas Praktiknya di Kec. Praya Lombok Tengah”, dalam Jurnal Penelitian Keislaman Lemlit IAIN Mataram, Vol. 4, No.2 (Juni 2008), hal. 271-290.

23 Dalam hadis disebutkan, mahar berupa cincin dari besi dijadikan mahar. Dalam hadis lain dituturkan seorang sahabat yang tidak punya harta sama sekali pun bisa menikah cukup dengan mahar membacakan beberapa Surat dalam Al-Qur'an. Lihat Muslim, Sabib Muslim, Jilid I, (Kairo: Dar Ihya' al-Kutub al-Arabiyah, tt), hal. 596. 
(mu amalah) yang tetap dipertahankan. Hal ini lazim dilakukan dalam rangka mempertahankan tradisi yang cenderung mengakar dalam masyarakat Sasak dengan meminta pesuke relatif "mahal".

Meskipun hal demikian secara normatif tidak dikehendaki oleh nash agama, namun praktik dalam masyarakat tetap berlangsung terus, bahkan dengan jumlah hingga puluhan juta rupiah. Masyarakat banyak dimotivasi oleh kecenderungan mereka dalam mengklaim tradisi yang dipraktikkannya itu adalah perbuatan yang baik, yang dalam ilmu ushûl fiqh disebut sebagai 'urf. ${ }^{24}$ Dalam kondisi munculnya ketegangan antara norma agama dan tradisi ini kemudian terjadilah negosiasi. Bagi masyarakat yang mampu mereka tetap memberikan pesuke meskipun itu mahal, tetapi bagi yang kurang mampu terjadilah tawar-menawar yang kemudian sampai pada "harga perdamaian". Dengan demikian tampak jelas, corak keberagamaan dalam tradisi merariq mencerminkan dialog antara Islam dan kultur lokal dengan tidak saling menegasikan. Keduanya sama-sama diakui, dihargai, dan diimplementasikan sesuai konteks sosial dan personal bagi pelakunya.

\section{Penutup}

Islam lokal pada dasarnya mencerminkan suatu bentuk Islam kreatif yang dikonstruks melalui proses dialektik. Dalam proses ini terjadi saling mendukung, memberi dan menerima, melalui interaksi secara terus-menerus dengan tidak memandang remeh masuknya unsur lokal. Islam Sasak tidak semata transfer dari Timur Tengah, tetapi sekaligus merupakan kombinasi yang kreatif dengan budaya setempat. Dua pola keberagamaan komunitas Wetu Telu dan Islam Waktu Lima tetap dapat hidup berdampingan, bahkan saling mengisi sebagaimana terlihat dalam sejumlah ritual.

Pada akhirnya, kedua pola keberagamaan itu tidak perlu dipertentangkan. Yang justru penting diagendakan pada masa kini, dan terlebih juga masa depan, adalah mengembangkan corak keberagamaan kolaboratif sehingga menghasilkan potret Islam Sasak yang dinamis, ramah terhadap budaya lokal, dengan tanpa kehilangan nilai dasar otentisitas Islam itu sendiri.

24 Urf secara etimologi bararti sesuatu yang dipandang baik, yang diterima akal sehat. Menurut kebanyakan ulama, urf dinamakan juga adat karena merupakan perkara yang sudah dikenal dan berulang kali dilakukan. Lihat Muhammad Salam Mazkur, Madkhal ilâ al-Fiqh al-Islâm, (Kairo: Dar al-Qaumiyyah, 1964), hal. 120. 


\section{DAFTAR PUSTAKA}

Bartholomew, John Ryan. 2001. Alif Lam Mim: Kearifan Masyarakat Sasak, alih bahasa Imron Rosyidi. Yogyakarta: Tiara Wacana.

Bruinessen, Martin van. 1992. Tarekat Naqsyabandiyah di Indonesia. Bandung: Mizan.

Budiwanti, Erni. 2000. Islam Sasak Wetu Telu versus Waktu Lima, alih bahasa Noor Cholis dan Hairus Salim HS Yogyakarta: LKiS.

Geertz, Clifford. 1970. The Interpretation of Culture. London: Sage Publication. Mahasin. Jakarta: Pustaka Jaya.

Kartadarmadja, Soenyata dan Sutrisno Kutoyo, ed. 1978. Sejarah Kebangkitan Nasional Daerah NTB. Jakarta: Pusat Penelitian Sejarah dan Budaya Depdikbud.

Madjid, Nurcholish. 1992. "Islam dan Budaya Lokal: Masalah Akulturasi Timbal Balik", dalam Islam Doktrin dan Peradaban. Jakarta: Paramadina.

Mansyur, Zainuddin. 2005. “Tradisi Maulid Nabi dalam Masyarakat Sasak”, Jurnal Ulumuna Vol. IX Edisi 15 No.1 Januari-Juni.

Marrison, Geoffrey E. 1999 . Sasak and Javanese. Leiden: KITL V Press.

Mazkur, Muhammad Salam. 1964. Madkhal ila al-Fiqh al-Islam. Kairo, Dar al-Qaumiyyah.

Muslim. Tt. Sabih Muslim, Jilid I. Kairo: Dar Ihya' al-Kutub al-Arabiyah.

Mustafa, Abdullah dan Zaenuddin Mansyur. 2008. "Fenomena Pesuke pada Adat Perkawinan Suku Sasak: Kajian Sosiologi Hukun Islam atas Praktiknya di Kec. Praya Lombok Tengah", Jurnal Penelitian Keislaman Lemlit IAIN Mataram, Vol. 4, No.2, Juni.

Noer, Deliar. 1996. Gerakan Modern Islam di Indonesia 1900-1942. Jakarta: LP3ES.

Salam, Solichin. 1992. Lombok Pulau Perawan: Sejarah dan Masa Depannya Jakarta: Kuning Mas.

Syakur, Ahmad Abd. 2006. Islam dan Kebudayaan Sasak; Studi tentang Akulturasi Nilai-Nilai Islam ke dalam Kebudayaan Sasak. Yogyakarta: Pascasarjanan IAIN Sunan Kalijaga. 
Team Penyusun, 1977. Monografi Daerah Nusa Tenggara Barat. Jakarta: Departemen Pendidikan dan Kebudayaan.

Tibi, Bassam. 1991. Islam and the Cultural Accommodation of Social Change. San Francisco: West view Press.

Tim Departemen P dan K, Adat dan Upacara Perkawinan Daerah Nusa Tenggara Barat. Jakarta: Depdikbud.

Tim Penyusun. 1992. Profil Propinsi NTB. Jakarta: Yayasan Bhakti Wawasan Nusantara.

Umam dkk, Fawaizul. 2007. Membangun Resistensi. Merawat Tradisi: Modal Sosial Komunitas Wetu Telu. Mataram: LKiM.

Wahid, Abdurrahman. 2001. Pergulatan Negara, Agama, dan Kebudayaan. Jakarta: Desantara.

Woodward, Mark R. 1999. Islam Jawa: Kesalehan Normativ versus Kebatinan, terj. Hairus Salim. Yogyakarta: LKiS.

Yasin, M. Nur. 2006. "Kontekstualisasi Doktrin Tradisional di Tengah Modernisasi Hukum Nasional Studi tentang Kawin Lari (merariq) di Pulau Lombok", Jurnal Istinbath Fak. Syariah IAIN Mataram, Vol. 4, No. 1, Desember.

Zaelani, Kamarudin. 2005. "Dialektika Islam dengan Varian Kultur Lokal dalam Pola Keberagamaan Muslim Sasak”, Jurnal Ulumuna IAIN Mataram, Vol. IX Edisi 15 No.1 Januari-Juni.

Zakaria, Fathurrahman. 1988. Mozaik Budaya Orang Mataram. Mataram: Yayasan Sumurmas Al-Hamidy. 